\title{
Coordination of care increases the quality of care and reduces costs
}

\section{Abstract}

The study addresses a health care model of the elderly practiced by a health care provider in the city of Rio de Janeiro, RJ, Brazil, focusing on the age group of the elderly, population segment in which the greatest misconceptions are identified. The current assistance models did not consider the deep transformations observed in the new epidemiological and demographic reality of the country. Considering that the aging process in Brazil is relatively recent, the article presents a proposal for a contemporary care model, recommended by the most important national and international health agencies as the most suitable for better care, focusing on the promotion, prevention of health care and the coordination of care, in order to avoid excesses, waste and fragmentation. The assistance and financial results of this study display very positive figures and indicate the path to be taken by healthcare companies. The model of remuneration for service providers and the indicators used for the establishment of bonuses are also presented, since they function as an instrument that stimulates and values good health care practices. This text is concerned with a higher quality, more resolutive and cost-effective care model, which is corroborated by the operator's results presented here.

\footnotetext{
Universidade do Estado do Rio de Janeiro (UERJ), Universidade Aberta da Terceira Idade. Rio de Janeiro, RJ, Brasil.

2 Caixa de Assistência à Saúde (CABERJ), Gerência de Saúde. Rio de Janeiro, RJ, Brasil.

3 Caixa de Assistência à Saúde (CABERJ), Direção de Saúde. Rio de Janeiro, RJ, Brasil.

Renato Peixoto Veras' (D) João André Cruz Gomes² Sandro Tadeu Macedo ${ }^{3}$ ID

Keywords: Health policies. Human aging. Elderly. Diseases prevention. Coordination of care. Payment for performance. 


\section{INTRODUCTION}

One of mankind's greatest accomplishments has been to achieve longevity, which has been accompanied by a substantial improvement in the health parameters of populations, although these achievements have been far from equitably distributed in different countries and socioeconomic contexts. Reaching old age - once the privilege of a few - has become the norm even in the poorest countries. The challenge, therefore, is to add quality to these additional years of life.

This demographic transition and the improvement in Brazil's social and economic indicators, compared to previous decades, have led to the expansion of the elderly population and greater fiscal pressure on public and private health systems. If this portion of the population increases, chronic diseases and expenditures also naturally increase ${ }^{1}$. One of the results of this dynamic is the growing demand for health services, which can simultaneously generate scarcity and/or resource constraints. Hospital admissions become more frequent and bed occupancy times are greater than in other age groups. The diseases that affect the elderly are mostly chronic and multiple, require constant monitoring, permanent care, continuous medication and periodic examinations ${ }^{2}$.

With so many adverse situations, care of the elderly should be structured in a special manner. The current provision of health services fragments care for this age group, with multiple expert consultations, non-sharing of information and numerous drugs, clinical and imaging exams, among other procedures that overload the system, have a serious financial impact at all levels and do not generate significant benefits for health or quality of life ${ }^{3}$.

In recent decades, it has been shown that most of the public health problems affecting the population - not only communicable but also noncommunicable diseases - can be prevented. This is exemplified by the reduction in mortality due to cardiovascular disease, a reduction in the incidence and mortality of cervical cancer, the prevalence of smoking and the incidence of lung cancer in men. In summary: the burden generated by diseases can be avoided in both social and economic terms ${ }^{4}$.
The monitoring of the health conditions of a given population, as well as their associated factors, is a key instrument for guiding prevention strategies, which should aim to: favorably affect the natural history of the disease; anticipate the appearance of complications; prevent exacerbations and complications of chronic diseases; increase patient involvement in self-care; and build a database of the chronically ill, that is, the overwhelming majority of the elderly.

According to the World Health Organization (WHO), a chronic disease has one or more of the following characteristics: it is permanent, produces incapacity or disability, is caused by irreversible pathological disorders and requires long periods of supervision, observation or care. In general, chronic diseases begin slowly, have a long or uncertain duration, and do not have a single cause $^{5}$. The treatment involves changes in lifestyle and continuous care that does not usually lead to healing, but allows the disease to be kept under control and improve the patient's quality of life, in order to prevent or ameliorate functional decline. Most chronic diseases are related to age, poor eating habits, sedentary lifestyles and stress, and so can be prevented and/or delayed. It means that despite the disease, it is possible to live a fuller life for a longer time.

Programs aimed at this population should be built on the basis of integral care, with the reference health professional and their team playing a leading role, managing not the disease, but the health profile of the patient. Often, the treatment of a manifestation can only be carried out with the reduction or suspension of other actions that were being performed ${ }^{5}$.

\section{A contemporary model}

In projects outside Brazil, a general practitioner or family doctor deals with $85 \%$ to $95 \%$ of their patients, without the need of a specialist. In addition, this doctor can employ health professionals with specific training (in nutrition, physiotherapy, psychology, speech therapy, and other specialties). It is the general practitioner who makes recommendations and referrals ${ }^{6}$. 
The English model, the National Health Service (NHS), employs generalist medical figures with highresolutive capabilities - so-called general practitioners (GPs) - who establish a strong bond with their patients. Access to these professionals is guaranteed to everyone regardless of income or social status, similar to the Brazilian Unified Health System (or SUS). When registering with a GP, British citizens receive free public health care in units composed of general practitioners and nurses. Any necessary treatment, provided it is not of extreme urgency or due to an accident, is performed there ${ }^{7}$. The American model, on the other hand, chooses to refer patients to numerous medical specialists. These are two rich countries, with great medical traditions. However, they use different systems and produce quite different results ${ }^{8}$.

In Brazil there is an excess of consultations by specialists, as the current care model prioritizes the fragmentation of care ${ }^{9}$. However, the discussion about population aging brought about by the new epidemiological and demographic reality suggests a need for the creation of a more resilient and effective model $^{10}$. One question therefore emerges: if everyone is discussing this issue and the solutions are already part of decision-making meetings, why is the situation unchanged? Why do leaders and managers not change the situation?

In order for the health sector - particularly in the elderly segment - to reorganize itself, one of the items to consider is trust. Today society is suspicious of what is offered. In this climate, any proposal for change is viewed with reservations. Anything that is multifactorial and built over many years is difficult to transform ${ }^{11}$.
Quality of care demands greater awareness among health managers and society. It is argued that it would be expensive to apply instruments that provide more qualified care, accreditations and certifications, yet good services are more effective in terms of cost, generate less waste and better patient care results. In some countries, accreditation and the evaluation of quality indicators are mandatory requirements. In Brazil, however, volume is valued and rewarded. A policy of stimulating quality is lacking. Patients do not always recognize it as a necessity. And both the public and private health systems perceive it as an additional cost.

\section{Explosive costs}

A recent study by the Organization for Economic Cooperation and Development (OECD) in developed countries shows the difference between health care costs in the United States and other rich countries which offer good quality care - where, of course, health care expenditures are greater than in developing countries. Still, the spending of the Americans is higher. In 2017, it was US\$ 10,224 per person, 28\% higher than Switzerland and more than double the United Kingdom (see Figure 1). These data reinforce the view that mass investment in disease treatment is not enough. Considering the aging of the global population, health costs tend to be an increasing burden for society, as shown in Figure 2. This demonstrates a reduction in the costs of activities that require the use of new technologies, as opposed to costs related to hospital services. It is imperative to change the logic of care ${ }^{12}$. 


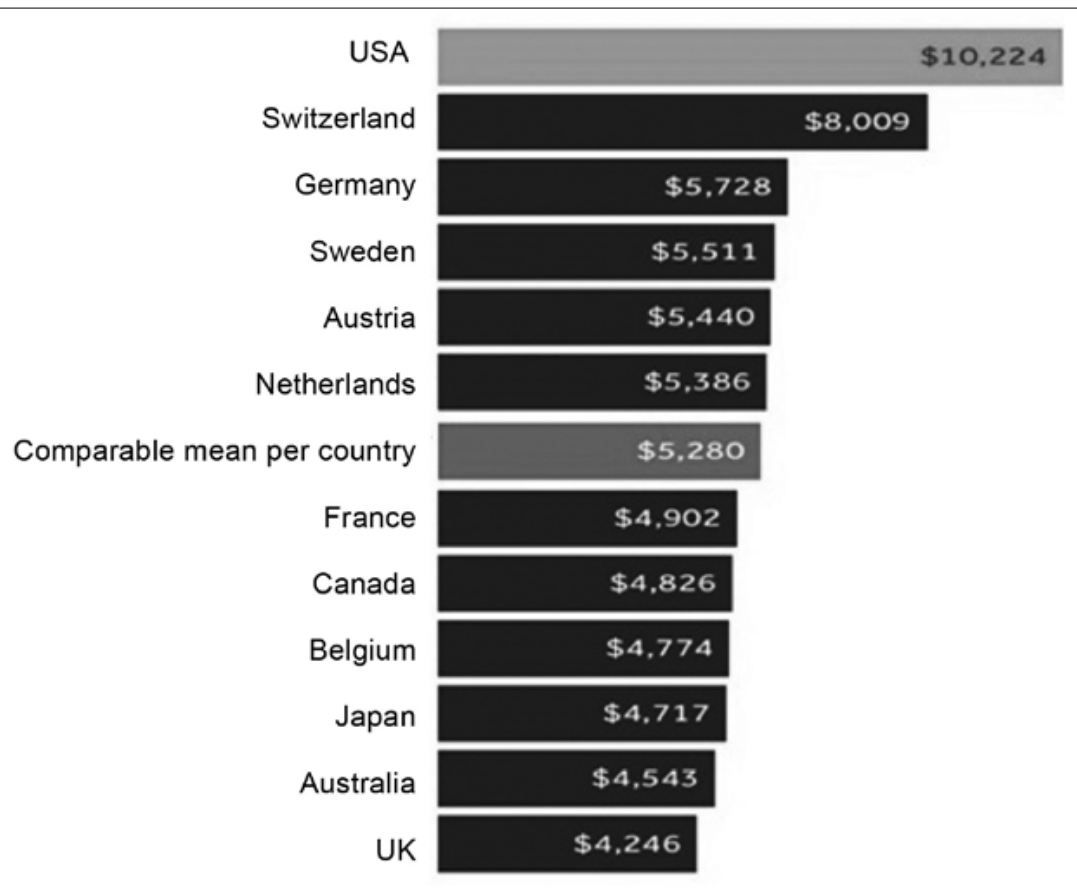

PPP: Purchasing power parity is a way of measuring economic variables in different countries, so that irrelevant changes in the exchange rate do not distort comparisons.

The US value was obtained from the 2017 National Health Expenditure data.

Source: KFF analysis of data from National Health Expenditure Accounts and OECD - Get the data - PNG. Peterson-Kaiser, Health System Tracker:

Figure 1. Health costs per capita, US dollars, adjusted by Purchasing Power Parity (PPP), 2017.

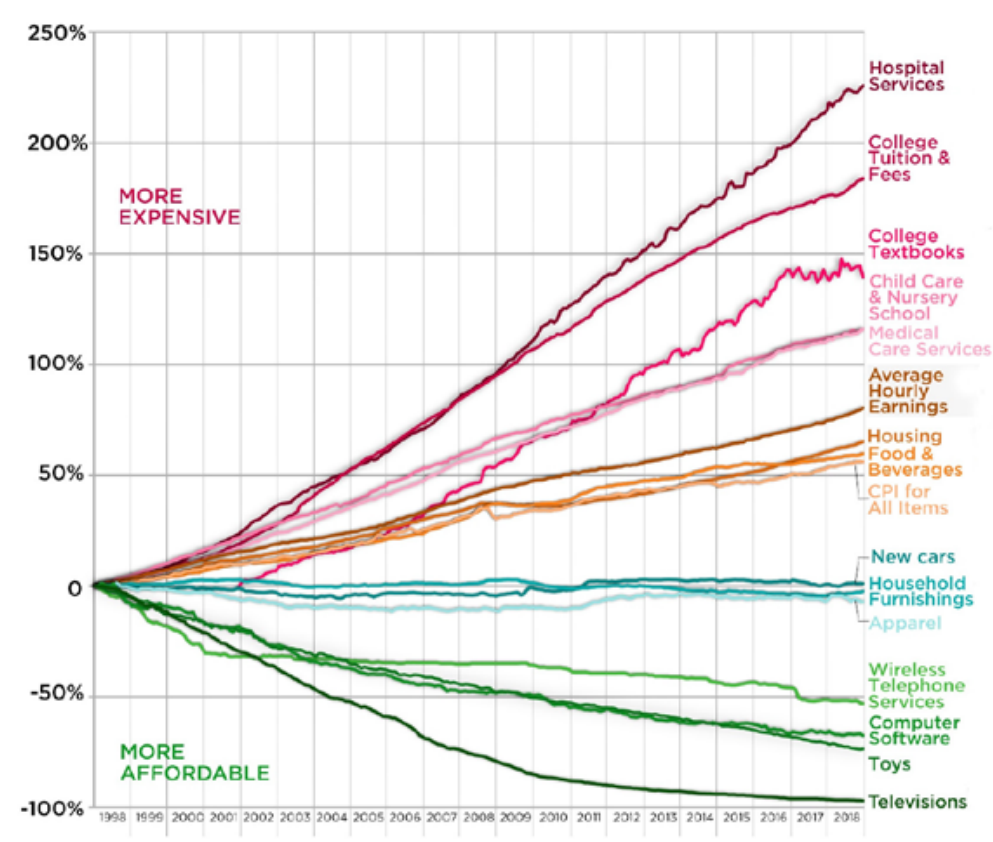

Source: Price Changes Over the last 20 years prove the economy is rigged (https://howmuch.net/article/price-changes-in-usa-inpast-20-years).

Figure 2. 20 years of price changes in the USA. Goods and Services of selected consumers, salary (Jan. 1998 to Dec. 2018). 


\section{The innovation required}

Care must be organized in an integrated manner and must be coordinated along the care path, in a network of logic, from entry into the system to care at the end of life ${ }^{13}$. Suitable models of health care for the elderly offer a proposal for a line of care focused on actions of education, health promotion, prevention of preventable diseases, postponement of illnesses, early care and rehabilitation ${ }^{14}$. The model should be based on the early identification of the risks of user frailty. Once risk is identified, the priority is to intervene before the event occurs, reducing the impact of chronic conditions on functionality. The idea is to monitor health, not the disease. Thus, the best strategy for proper care is to use the logic of permanent accompaniment, varying only the levels, intensity and scenario of the intervention ${ }^{15}$.

There is a general understanding that care for the elderly goes beyond health. In addition to diagnosis and prescription, social participation, physical and mental activities are important elements for maintaining functional capacity. But especially in supplemental health, there is still much difficulty in understanding these actions as an integral part of care - a tendency to separate "social" from "healing" actions. It is also of fundamental importance, especially today, that quality information and electronic medical records register both clinical and "social" actions, and that this registry is available in the cloud and accessible by mobile, so that doctors and other health professionals can monitor the client at any time.

Regarding the remuneration model of health professionals, why not adopt performance related pay? Linking results to the form of remuneration is a powerful tool for quality of care. And the model should be of the win-win type, in which all involved benefit, especially the patients.

In order to put into practice the necessary actions for a healthy aging with a good quality of life, care for the elderly must be rethought and redesigned with a focus on these individual and their particularities. This will bring benefits, quality and sustainability not only for the elderly population but for the Brazilian health system as a whole ${ }^{5}$. It is time to show the capacity to unite efforts that turn theory into a health model of universal quality. We do not desire the fragmentation of the SUS, nor the increase in the number of bankruptcies among private health care companies.

The challenge is to ensure this new care model is accepted by the client, as trust is an indispensable factor for the process to occur as planned - and one cannot ask someone to trust something they know nothing about. There is little point in saying that this model is the best if it is not implemented by supplementary health services. Society needs to understand this proposal extensively to be convinced of its benefits ${ }^{16}$. Otherwise, it will continue to opt for the "siren song" of excess and consumption, which burden the system, generate ever higher costs and render long-term care unfeasible.

\section{Well-executed care coordination}

We shall now demonstrate the successful experiment performed by a health care provider in two of its units in the city of Rio de Janeiro. The study focuses on the performance indicators of the company, which offers a specific program for the elderly population that has been providing excellent results.

The change in care logic encountered some resistance from health professionals and especially from clients, who were reluctant to accept having fewer doctors to rely on. After the first year of the new model, however, the situation has changed. The present study provides an analysis of a 12 month period - March 2018 to February 2019 - as a demonstration that it is possible to change results for the better and generate loyalty.

The geriatrics and gerontology program has two units in the city of Rio de Janeiro, in the neighborhoods of Copacabana and Tijuca, regions with a high proportion of elderly persons. Care is provided by general practitioners and geriatricians, as well as specialized multiprofessional teams (nurses, physiotherapists, nutritionists, psychologists and social workers). 
Now in its fifth year of operation, the program is structured in the form of a care model that focuses on integral care and prevention through the continuous monitoring of the health conditions of its members and the coordination of all settings of care. The present survey considers the total results of the units, without distinguishing between location, as the model practiced is exactly the same in both.

This health care provider provides care to clients aged 40 and over, but its largest concentration of patients is in the 60 to 79 years range, representing $76.7 \%$ of its clientele. The average age of clients is 69.1 years. Clients with chronic diseases, unhealthy living habits or with a pre-disposition for such pathologies are accepted. Entry occurs through active searching, spontaneous demand, medical recommendation and de-hospitalization.

The centrality of the model is based around the managing or attending physician. This is the health professional who guides the process. If an opinion or intervention by another colleague is required, he or she will refer the patient to a specialist. The handling of the case, however, is the responsibility of this attending physician. After consultation with the specialist, everything is recorded in the patient's individual medical record.

The program is based on a pairing formed by a general practitioner (qualified geriatrician) and nurse. Together, they have the responsibility of monitoring the health of around 360 patients. The doctor, who works 20 hours a week, performs clinical management; the nurse, the coordination of care, monitoring the health conditions of their client list and consolidating their reference role through reception and the strengthening of bonds.

The proposal of welcoming, monitoring and providing health support within a broad concept that considers clinical stabilization as a constant goal is one of the premises of the program. Its efficacy is attested by the financial results obtained, which is only possible with the high levels of adherence of the participants, who perceive they are receiving more intense care.
In these health units, an important space is the social center, which has a fundamental role as a place of integrating several actions of promotion, prevention and education. There are meetings and interactions with pedagogical goals, aimed at the elderly, such as health workshops, therapeutic groups, yoga, ballroom dancing, psychology groups, nutrition, singing, postural orientation, pelvic and muscular strengthening, with the participation of multidisciplinary professional teams. This is a set of professionals from different academic backgrounds who contribute the specific tools of their area of knowledge and performance. The objective is to reduce the problems of solitude among the elderly, to improve their social contact and to develop new abilities at a later age, as this is a stimulating space for the exchange of experiences, mediated by a pedagogical approach.

\section{Entry}

When there is interest in joining the program, an initial interview with the management team is scheduled. At this point, the basic premises are described, such as the single line of medical care, the importance of attending consultations regardless of symptoms or suffering from an active disease, and the monitoring process.

Initially, the functional evaluation of the elderly is carried out using the Functional Clinical Vulnerability Index-20 (IVCF-20) tool for the stratification of the risk of frailty. Throughout the process, other scales are also used, such as the Basic Activities of Daily Living Scale (Katz Scale), the Geriatric Depression Scale (Yesavage Scale) and the Instrumental Activities of Daily Living Scale (Lawton Scale) ${ }^{17-19}$. Following this evaluation, the geriatrician and nurse pairing define an individual therapeutic plan with periodic consultations, referral to multidisciplinary teams and social centers and, if necessary, the evaluation of medical specialists.

For the success of the model, it is fundamental that the client is informed about its unique characteristics: integrality, individualized care from the attending 
physician and nurse, constant evaluations, the support of a health team and the overall nature of the care. The program is part of a prevention platform that includes palliative care projects, multilevel home care, reception and targeted hospital care, which is the network of the internist doctors of the health providers who accompany members in certain hospitals where there are exclusive beds for this purpose.

By monitoring health rather than illness, the model directs the investment of system resources towards early intervention, resulting in more generous chances of rehabilitation and a reduced impact on functionality.

\section{Doctor remuneration}

Performance-related pay was established by the provider for this specific program and establishes bonus levels of up to $30 \%$ in compensation per quarter. Every three months, an evaluation of the performance of the professional is made based on previously determined indicators. Each point obtained adds a bonus of $5 \%$ of his or her salary.

One of the evaluation items is the percentage of consultations of the doctor's patient list every quarter. As one of the premises of the program is that there is a need for four medical consultations per year, quarterly consultations is required for all clients linked to the doctor. In other words, every client of the program is attended by their doctor four times a year. Non-attendance situations are analyzed on a case-by-case basis.

Attendance and punctuality are prerequisites of the bonus system, and are fundamental for guaranteeing the number of consultations - a factor of quality for the operation of the service. Another requirement of the scoring program is the proper recording of information and possible hospitalizations in the electronic records of clients. Rigid control by the team determines the economicfinancial success of any initiative or project.
The bonus was initially established only for geriatricians, but the success of this mode of remuneration was such that the company decided to extend the benefit to all healthcare staff. The items chosen for the establishment of differentiated performance criteria are related to the theoretical principles that guide the actions being carried out. As established assumptions, these indicators are constantly evaluated.

A customer satisfaction survey in line with the methodology of the Net Promoter Score (NPS) is continuously performed in the healthcare units of the provider. One of the issues is an assessment of customer satisfaction with doctors. Al the doctors of the program at this provider are geriatricians with at least one postgraduate qualification. This is a requirement because professional excellence is a key to success.

Another basic principle is the resolutive capacity of the geriatrician. According to international studies ${ }^{7}$, a general practitioner can resolve from $85 \%$ to $95 \%$ of the clinical situations of his or her clientele. Referrals to clinical specialists are the exception. The referral of up to $15 \%$ of clients on a doctor's patient list in a single quarter demonstrates good resolutive capacity, worthy of bonus points.

The engagement of users with the multidisciplinary team and the social center determines their bond with the program and its resolutive capacity. Thus, an item was included that evaluates the participation of the members of each patient list in consultations with the gerontologists of the team and in the collective activities of the social center, earning bonus points.

The main economic-financial indicator established for the evaluation of the program is the loss-ratio, which is why a greater weight was given to this item, and doctors can score up to two points in the evaluation of their performance in this category. By analyzing the recent history of the results, ambitious points goals were set. Although there is greater rigidity with this evaluation, the desired goals are already being achieved, and the win-win based stimulus to the professionals has been seen to be fair. 
Bonus scoring

The items from the records of each physician evaluated quarterly are as follows:

1. Consultation percentage

a. Consultation rate of $100 \%$ of patient list (1 point).

b. Consultation rate of $90 \%$ to $99 \%$ (no points).

c. Consultation rate below $90 \%$ (minus 1 point).

2. Client satisfaction survey (over $90 \%, 1$ point)

3. Resolutive capacity of doctor

a. Use of network for less than $15 \%$ of cases (1 point).

b. Use of network of $80 \%$ to $85 \%$ (no points).

c. Use of network lower than $80 \%$ (minus 1 point).

4. Participation in social center/workshops/ multidisciplinary team activities.

a. Over $20 \%$ of clients from patient list (1 point).

b. From 10 to $19 \%$ (no points).

c. Below $10 \%$ (minus 1 point).

5. Medical loss ratio of patient list
a. Below $70 \%$ (2 points).
b. From $70 \%$ to $79 \%$ (1 point).
c. From $80 \%$ to $99 \%$ (no points).
d. $100 \%$ (minus 1 point).

For privacy reasons, the results of the bonuses of the doctors are not provided here. In terms of general information, however, all the doctors on the program have been subsidized in every quarterly evaluation. Variation occurred in the value of the bonus, because the percentages of some were superior to those of others.

\section{Transition of care - hospitalizations}

One of the main factors for controlling the costs associated with the program is patient accompaniment in each care setting. There should be no gaps in care when the patient is referred to the care network or when they require tertiary or hospital care.
The transition between care settings is accompanied by the management team, who emphasize the importance of the fluid flow of information, approaching the attending health professionals and seeking to preserve the principle of the predominant guidance of the geriatric doctor and nurse pairing.

The control of hospitalizations occurs via a determined flow in order to assist the clients, ensuring that caregivers are aware of their medical and treatment history, as well as understanding that such patients receive frequent follow-up monitoring and should return to their health team when the period of clinical risk is over.

In case of hospitalization, the patient is monitored on a daily basis through two strands. In one, the nurse maintains contact with the family to provide support, clarification or identification of needs (the patient's or the family's). The other involves a prevention manager, who acts as a liaison between the outpatient clinic and the hospital, with daily follow-up with the attending physician at the hospital. In hospitals where there is an internist (68\% of hospitalizations of the program), this contact is facilitated and direct. In the others there is the support of the medical auditors or the care team.

With this aim being fulfilled, it can be attested that elderly hospitalization occurs more quickly, avoiding unnecessary procedures or hospitalizations in intensive care sectors, guaranteeing postdischarge guidance for mild care settings, without the need for consultation with various specialists. Everything converges into a higher quality of care with significant cost reductions, positively impacting the medical loss ratio among this group of patients.

\section{RESULTS}

The results of the operator studied are extremely positive and demonstrate the success of the model. The medical loss ratio has continuously decreased. In its first year, there was a negative impact, as the medical loss ratio was $108.20 \%$. This rate refers to the first year of the project, reflecting the period 
in which the clients were still receiving inadequate treatment from many doctors and hospitals. But from the second year onwards the numbers improved and better results were obtained in subsequent years, reaching the impressive mark of $56.6 \%$ in the final year (figure 3).

The medical loss ratio in 2018 was $61.8 \%$. The figure 4 shows the month by month performance.

The medical loss ratio results of the final year of the program are below the expected level for the 60 years or older age group.

Another indicator that demonstrates excellent results is hospital admission. In the two units of the operator, there are 1,832 clients. In the last 12 months, there were 238 hospitalizations, totaling 1,160 days, with an average length of stay in the hospital unit of 4.9 days. The monthly average was 19 admissions and the hospitalization rate per 100 inhabitants was 12.99 - or 129.90 per thousand clients.
The statistics of the National Supplementary Health Agency (or ANS) were compared in terms of the hospital admissions of beneficiaries of the various modalities of Brazilian health care providers. In several years and across all comparisons, the results of the company studied herein were better ${ }^{20}$.

It should also be noted that the ANS data comprise participants from all age groups, while the program of the provider studied here mostly involves the elderly. It would therefore be natural to imagine that the ANS numbers, as they include a significant proportion of young adults and children, would be superior (figure 5).

The chart shows (figure 6) the comparison of the hospitalization rate per thousand beneficiaries of the Program studied with self-management operators and also with the average of all health care providers in 2015, 2016 and 2017. The Program group is the result of the operator studied, followed by the selfmanagement group, and all the health care providers for the years studied.

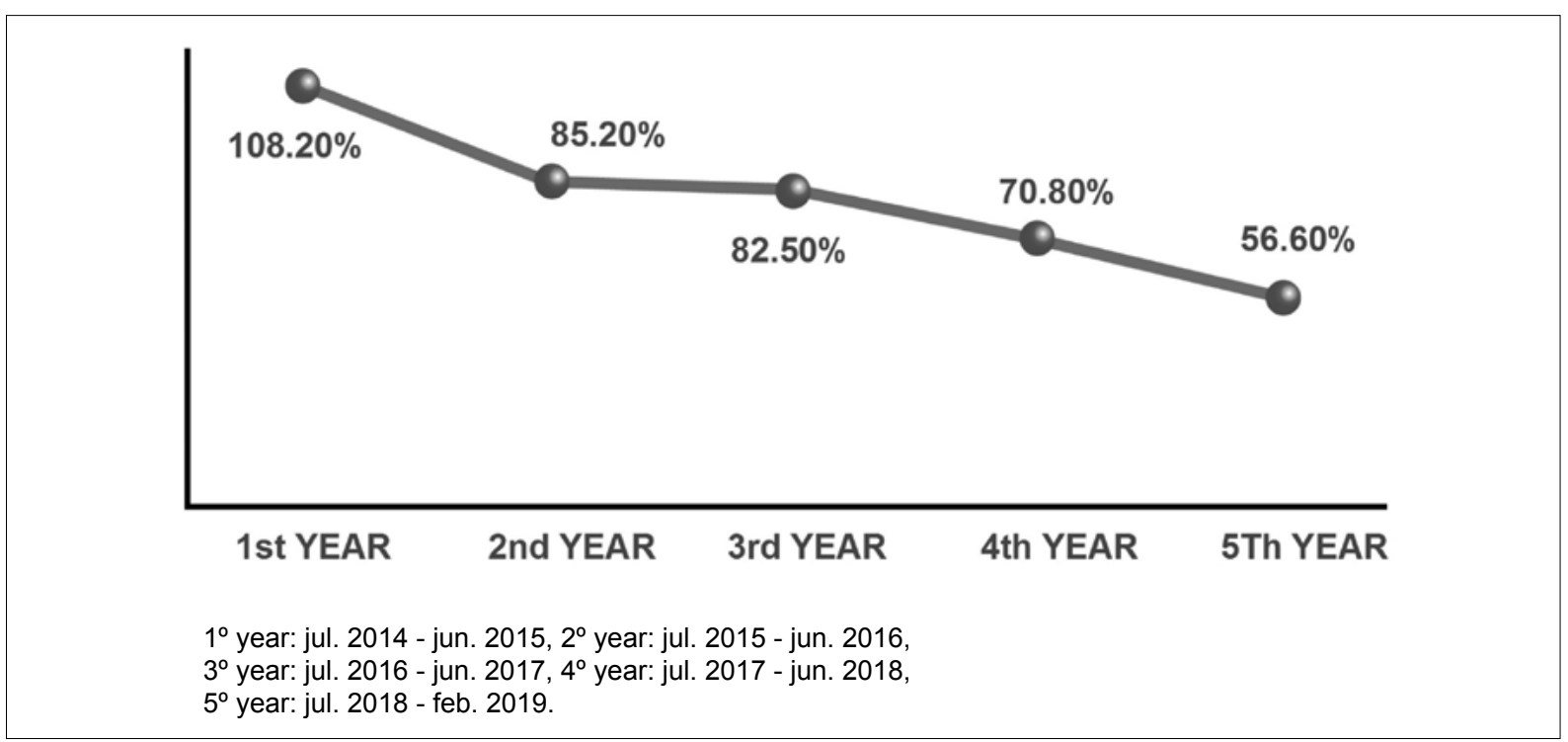

Figure 3. Medical loss ratio in last five years. 


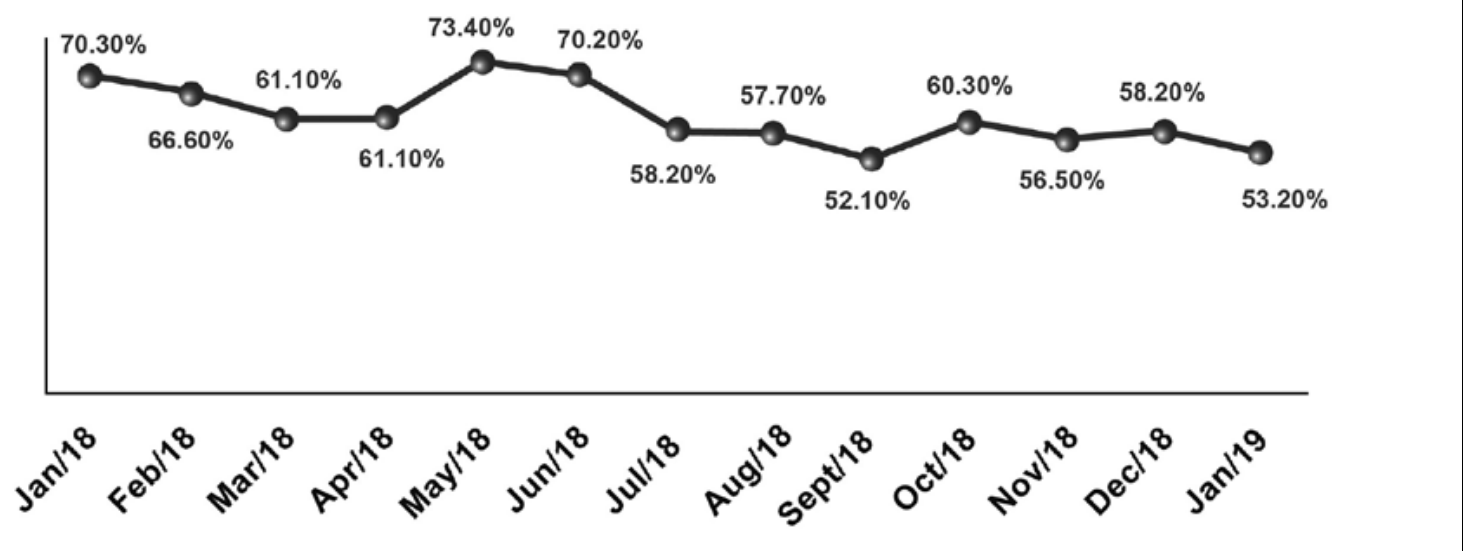

Figure 4. Month by month medical loss ratio 2018-2019.

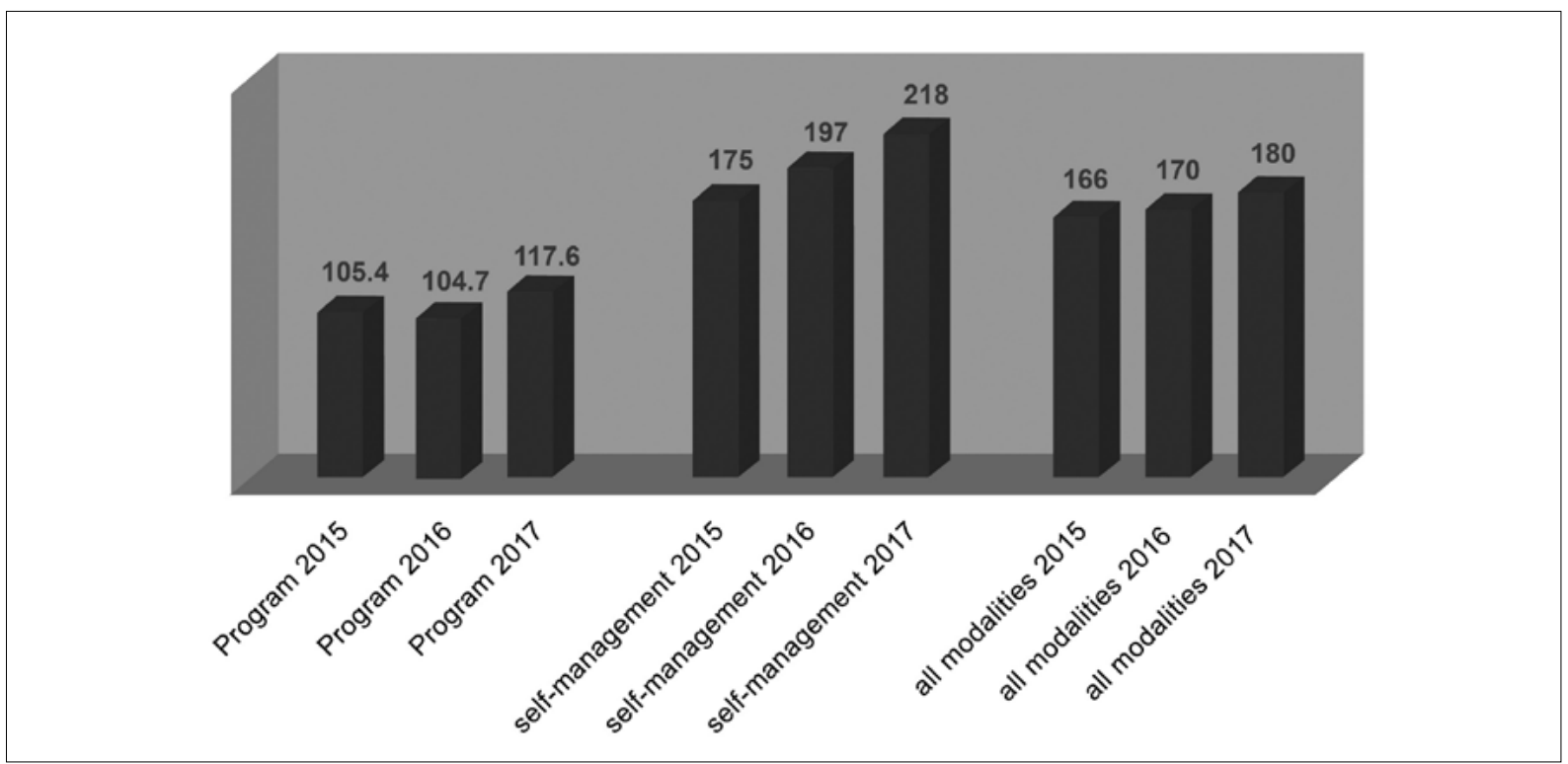

Figure 5. Hospitalization rate of studied groups.

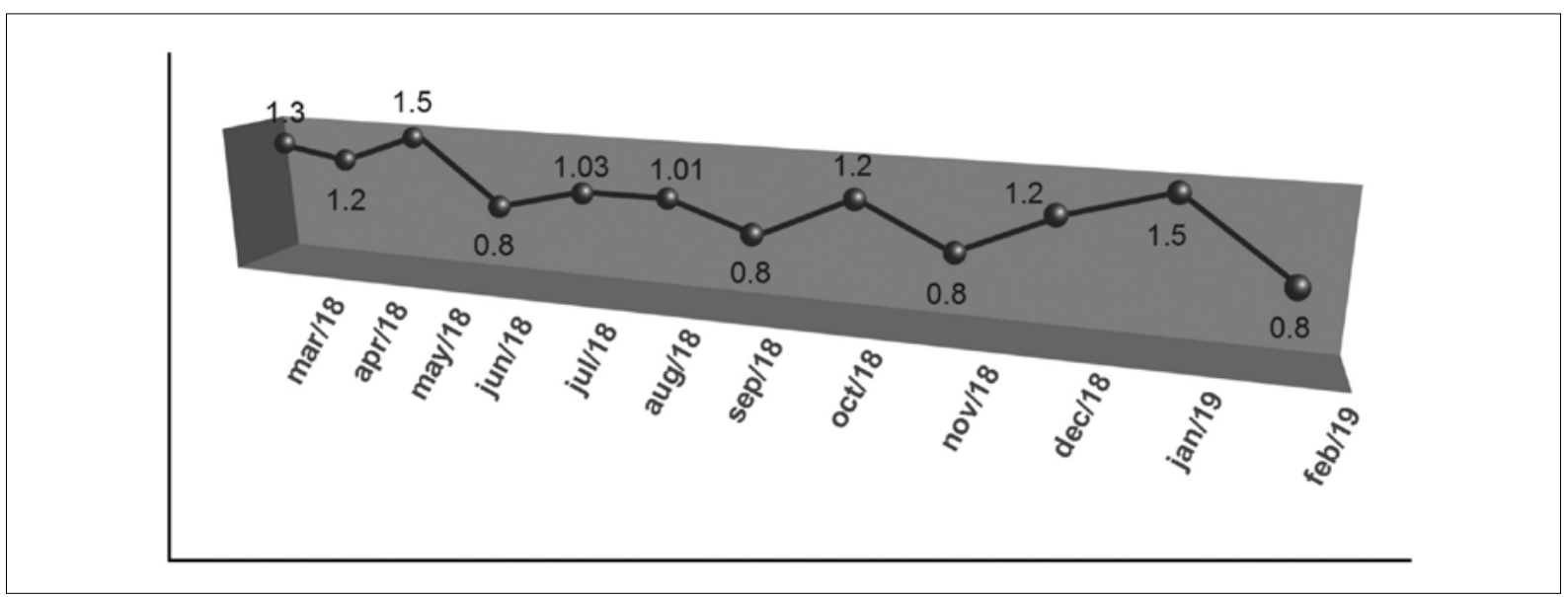

Figure 6. Hospitalization per 100 registered clients. 
The analysis of the monthly hospitalization rate of the Program indicates that there is no major variation in the rate over time, demonstrating stability, the result of the control established through continuous and effective monitoring.

\section{The importance of coordinating care}

There are a number of suggestions for models of lines of care. It is important that each health institution has knowledge of its list of patients, their profiles and needs, in order to organize the delivery of service in the best way possible.

The model of this provider is in line with studies that suggest the implantation of coordination of care. Considering the hospital as a privileged place for healing is a conceptual mistake, as there must be several care settings prior to this stage. In the case of the elderly, hospitalization should occur only at the acute moment of the chronic illness and for the shortest possible time, or in the emergency room. The gateway to the system should be a facilitating setting for the client and their family to feel protected and supported. A welcoming reception is fundamental for those who arrive at the health service and a stimulus to developing confidence and loyalty.

Another important aspect is the emphasis on client participation in the activities of the social center. The data demonstrate the positive effect of this on reducing referrals to medical specialists. Furthermore, the professionals who run the activities are identified as team members and therefore have good credibility among clients. The importance of an effective information system and the use of new technologies for more frequent contact with the clientele was also identified. Without comprehensive information, there can be no effective monitoring.

For ethical reasons, we have preserved the confidentiality of the name of the health care provider, which authorized the use of the data and information presented herein following a prior request. Although the results presented refer to a health care provider, as this is a model of care, the proposal of this article can be perfectly applied to the public service. Based on the justification that good health care models should be practiced in both the SUS and the private sector, a good model should be used by the Brazilian population without distinction, whether the care is public or private.

\section{CONCLUSION}

In summary, an efficient model of health care for the elderly should involve the application of all levels of care: a well-designed flow of education, health promotion, prevention of preventable diseases, as well as the postponement of diseases and rehabilitation from illness. It begins in capitation and reception and ends only in the final moments of life, in the palliative care unit.

In order to reorient the health care of the elderly population and to organize the sector to enable better economic-financial and care results, it is sufficient that all those involved perceive themselves as responsible for change and allow themselves to innovate - which, in many situations, means rescuing simpler forms of care and values that have been lost within our health system.

We do not deny the importance of highcomplexity forms of care and know that we will always need good hospitals. It is not logical, however, to turn hospitals into gateways to health systems.

It is vital that the debate on healing and care is included in discussions on vocational training and the organization of services. This transformation will make a great difference at this time of population aging, as we have learned that it is possible to grow old with sustainability, stable health and a good quality of life. 


\section{REFERENCES}

1. Veras RP, Estevam AA. Modelo de atenção à saúde do idoso: a ênfase sobre o primeiro nível de atenção. In: Lozer AC et al. (Orgs.). Conhecimento técnicocientífico para qualificação da saúde suplementar. Brasília, DF: OPAS; 2015. p. 73-84.

2. Szwarcwald CL et al. Percepção da população brasileira sobre a assistência prestada pelo médico. Cienc Saúde Colet. 2016;21(2):339-50.

3. Veras RP, Oliveira MR. Linha de cuidado para o idoso: detalhando o modelo. Rev Bras Geriatr Gerontol. 2016;19(6):887-905.

4. Carvalho VKS, Marques CP, Silva EN. A contribuição do Programa Mais Médicos: análise a partir das recomendações da OMS para provimento de médicos. Cienc Saúde Colet., v. 21, n. 9, p. 2773-84, 2016.

5. Veras RP, Oliveira MR. Envelhecer no Brasil: a construção de um modelo de cuidado. Cienc Saúde Colet. 2018;23(6):1929-36.

6. Veras RP. Experiências e tendências internacionais de modelos de cuidado para com o idoso. Cienc Saúde Colet. 2012;17(1):231-238.

7. Tanaka OU, Oliveira VE. Reforma(s) e estruturação do sistema de saúde britânico: lições para o SUS. Saúde soc. 2007;16(1):7-17.

8. Oliveira MR, et al. A mudança de modelo assistencial de cuidado ao idoso na Saúde Suplementar: identificação de seus pontos-chave e obstáculos para implementação. Physis: Revista de Saúde Coletiva. 2016; 26(4):1383-94.

9. Silva AMM et al. Uso de serviços de saúde por idosos brasileiros com e sem limitação funcional. Rev Saúde Pública. 2017;51(supl):1-10.
10. Oliveira MR, Veras RP, Cordeiro HA. Supplementary Health and aging after 19 years of regulation: where are we now? Rev Bras Geriatr Gerontol. 2017;20(5):624-33.

11. Veras RP. Caring Senior: um modelo brasileiro de saúde com ênfase nas instâncias leves de cuidado. Rev Bras Geriatr Gerontol. 2018;21(3):1-7.

12. Figueiredo JO, Prado NMBL, Medina MG, Paim JS. Gastos público e privado com saúde no Brasil e países selecionados. Saúde em Debate. 2018;42(esp2):37-47.

13. Mendes EV. As redes de atenção à saúde. Brasília: Organização Pan-Americana da Saúde; 2011.

14. Oliveira MR, et al. Idoso na saúde suplementar: uma urgência para a saúde da sociedade e para a sustentabilidade do setor. Rio de Janeiro: Agência Nacional de Saúde Suplementar; 2016.

15. Veras RP et al. Integração e continuidade do cuidado em modelos de rede de atenção à saúde para idosos frágeis. Rev Saúde Pública. 2014;48(2):357-365.

16. Moraes EM. Atenção à saúde do idoso: aspectos conceituais. Brasília, DF: OPAS; 2012.

17. Lourenço R, Perez M, Sanchez MA. Escalas de Avaliação Geriátrica. In: Freitas EV, et al. (Org.). Tratado de Geriatria e Gerontologia. Rio de Janeiro: Guanabara Koogan; 2011.

18. Moraes EM, Lanna FM. Avaliação Multidimensional do Idoso. Belo Horizonte: Folium; 2014.

19. Moraes EM; et al. Índice de Vulnerabilidade Clínico Funcional-20 (IVCF-20): reconhecimento rápido do idoso frágil. Rev. Saúde Pública. 2016;50:81.

20. Agência Nacional de Saúde Suplementar. Mapa assistencial da saúde suplementar de 2016. Rio de Janeiro: ANS; 2017. 